\title{
sciendo
}

\section{Analysis of the perception about the gender pay gap in the EU Member States}

\author{
Maria Denisa VASILESCU \\ The Bucharest University of Economic Studies, National Scientific Research Institute for \\ Labour and Social Protection, Bucharest, Romania \\ maria.vasilescu@csie.ase.ro \\ Gina Cristina DIMIAN \\ The Bucharest University of Economic Studies, Bucharest, Romania \\ gina.dimian@csie.ase.ro
}

\begin{abstract}
Amalia CRISTESCU
The Bucharest University of Economic Studies, National Scientific Research Institute for

Labour and Social Protection, Bucharest, Romania

cristescuamalia@gmail.com
\end{abstract}

\begin{abstract}
The main aim of the paper is to investigate European Union people's perceptions on the gender pay gap, concentrating on the differences between countries and social groups. The focus of our analysis is on the following research questions: a) Are people in countries with fewer low-wage earners more aware of the gender pay gap than the others? Are high educated people and older workers more affected by the gender pay inequalities? Descriptive statistics and logistic regression applied on 28093 observations extracted from EUROBAROMETER 87.4 (2017) confirmed the two hypotheses and brought in addition other interesting and somehow conflicting results. Namely, in some of the countries, people' perceptions are not supported by statistical data. In Luxembourg and Belgium, for example, even though statistical data demonstrate that the gender pay gap is between the lowest among European Union countries the percentage of those who perceives the inequalities is very high, exceeding $70 \%$ in both countries. More than that, in certain countries like Romania, a large number of people considers that gender pay gap is an acceptable phenomenon. Our contribution to the literature is two-fold. First, we have analysed the perceptions on gender pay gap of a large number of respondents and correlated with the reality demonstrated by statistical data. Second, we drew the attention to the fact that closing the 'gender pay gap' should be a target of public and private policies especially in high-wage countries, whereas in low-wage countries, the policy makers should focus rather on closing the 'countries pay gap', i.e. ensuring that wages are brought closer to the European average, with many economic and social benefits (raising living standards of the citizens, reducing poverty and migration and so on).
\end{abstract}

Keywords: gender pay gap, gender stereotypes, gender role, logistic regression, EU28.

\section{Introduction}

The gender pay gap is not only a reality proved by the statistical data, but also a persistent phenomenon whose causes different theories try to explain. The concept refers at the difference between female and male employees concerning the mean (gross) hourly earnings. Eurostat assesses this problem with the help of the indicator "unadjusted gender pay gap" which is expressed as a percentage of men's average gross hourly earnings.

At the European Member States level, the main characteristics of this phenomenon is the heterogeneity, while at individual level, a feature that deserves attention is the high 
proportion of the gender pay gap that remains unexplained (occurs in individuals with similar characteristics). For example, in 2017, the unadjusted gender pay gap ranged from 25.6\% in Estonia to 3.5\% in Romania. It was higher in financial and insurance activities and much lower in young employees 'case (EUROSTAT, 2018).

However, this indicator does not take into account all the factors that can cause the gender pay gap, i.e. differences between individuals related to the level of education, type of job, work experience or number of hour worked. In order to overcome this inconvenience and to measure the proportion of the gender pay gap that could be explained by the observed characteristics of men and women, Boll and Lageman (2018) applied a decomposition method, named Blinder-Oaxaca, and separated the unadjusted gender pay gap into two parts: explained and unexplained.

Thus, the authors pointed to some possible driving factors of the gender pay gap: sectoral gender segregation (i.e. in many countries women are moreover involved in lowpaying economic activities), occupational gender segregation (i.e. the concept of "glass ceiling" remains topical, meaning that men are still preferred for managerial positions to the detriment of women, and women seem to face some barriers when they try to rise into companies 'hierarchy), education level (women tend to have a higher level of education compared to men which could be, in general, a factor of gender pay gap reduction).

Governments are interested in reducing the gender pay gap, since the consequences could become worrisome: the higher risk of experiencing poverty for.

In United Kingdom, for example, the government proposes 6 effective actions, proved to have a positive impact in reducing gender pay gap: 1) Including multiple women in shortlists for recruitment and promotions; 2) Using skill-based assessment tasks in recruitment; 3) Using structured interviews for recruitment and promotions; 4) working women, for retiring women and even for children raised by single working mothers Encouraging salary negotiation by showing salary ranges; 5) Introducing transparency to promotion, pay and reward processes; 6) Appointing diversity managers and/or diversity task forces (https://www.gov.uk/government/news/uk-gender-pay-gap).

Taking into consideration all these aspects, our paper proposes to investigate European Union people's perceptions on the gender pay gap, focusing on the differences between countries and social groups. We expect that people in countries with fewer lowwage earners to be more aware of the gender pay gap than the others. In addition, it would seem like high educated people and older workers are more prone to be affected by the gender pay inequalities.

The structure of the paper is the following: after the introduction, the next section is dedicated to reviewing the main results of the literature, focusing on the methodology applied in order to measure gender pay gap, the principal findings and the implications for public policies. Section 3 presents paper methodology: descriptive statistics and logistic regression have been applied on 28093 observations extracted from EUROBAROMETER 87.4 (2017). Section 4 details the results of the applied methodology and demonstrates that there is not always a correspondence between people' perceptions and statistical data. The final part of the paper presents the conclusions and concentrates on the implications for public policies of the main findings of the paper.

In this regard, paper's contribution to the literature is the following: a) the perceptions on gender pay gap of a large number of respondents have been analyzed and correlated with the reality demonstrated by statistical data; b) we demonstrated that 
political solutions for closing the 'gender pay gap' should be tailored to the specifics of countries and individuals.

\section{Literature review}

The principle of equal pay for equal work is one of the pillars of social equity in the European Union. The existence of the pay gap, especially related to gender, made that a whole literature to be dedicated to identifying the causes of these differences. The gender pay gap seems to be country specific and even individual specific, but some factors have been identified to be the drivers of this phenomenon.

Besides gender, Beyer, Hensersky and Thomas (2019) reveal other important factors that should be taken into consideration when trying to understand gender pay gap: differences in negotiating skills, wage structure, occupational choice, differential childrearing responsibilities, discrimination or sexism.

The authors highlight the fact that the literature has shown that wage differences between men and women exist and that statistical data proved that the above mentioned factors have a significant impact.

However, the same authors have conducted a research in one of the US firm known for its increased interest in ensuring equal opportunities trying to demonstrated the hypothesis that even the pay gap exist, gender do not have a direct effect on it. The wage analysis of 317 project managers has demonstrated that even in this company there are wage differences between men and women. Still, conditional process modelling has revealed that gender does not have a direct effect on these differences in the situation where factors related to productivity (experience, performance, education) are taken into consideration.

Practically, the authors reinforce the results of Trevor, Teilly, and Gerhart, (2012), indicating that there is often a confusion between inequality and inequity.

In two emerging countries (Brazil and South Africa), for example, Ledwith and Munakamwe (2015) demonstrate that the gender pay gap is a persistent problem and it is related to multiple factors such as: race, gender, class or power.

Using the survey as a statistical method, applying questionnaires and conducting interviews, the authors point to the lack of participation of women in collective bargaining as one of the factors that can explain the persistence of the gender pay gap. As a solution, the aforementioned authors suggest treating the two aspects (gender leadership gap and gender pay gap) as parts of the same problem.

With the purpose to illustrate the role of the state in collective bargaining on ensuring gender equality (including equal pay), Milner, Demilly and Pochic (2018) analyzed 186 agreements and applied interviews in 20 companies. They proved that, although in France, the position of the state in these agreements is very strong, often the role of local actors is decisive. However, the authors draw attention to the fact that gender equality cannot be achieved without a strong state involvement.

Dias, Joyce and Parodi (2018), demonstrated that in the UK, gender pay gap is still large and that an important explaining factor is the working experience, especially for women who gave birth. The working part-time after the childbirth seems to action as a penalty factor for women earnings.

In the same sense, Rubery (2015) draws attention to a series of problems that the gender pay gap approach in the EU countries raises. For example, the author points to the fact that in the post-crisis period, the narrowing of the differences was mainly determined by 
the fact that men's salaries were reduced. This is practically not reflected in an increase in women's wages. Then, measuring gender pay gap raises a number of problems related to the difficulty of choosing the right indicators and identifying the parts (explained and unexplained) of the phenomenon. Finally, the author suggests that it is rather necessary to approach the gender pay gap at the entire economy level and not necessarily at each sector or occupation level.

\section{Methodology and data description}

The data used in this analysis come from the EUROBAROMETER 87.4 - Perception of Security and Gender Equality, applied in June 2017. The survey covered all 28 European Union Member States focusing on residents aged 15 years and over. The selection method used was Probability Sample - Multistage Sample. Data collection was done using face-to-face interviews - CAPI (Computer Assisted Personal Interview). The database contains 467 variables and 28083 units (European Commission, 2019).

The econometric analysis undertaken in this article is based on the logistic regression. This method is used to analyse the relation between a set of independent variables $x_{i}$ (categorical, continuous) and a dichotomous (nominal, binary) dependent variable $y$. Such a dependent variable usually occurs to indicate belonging to one of two possible classes: presence/absence, yes/no.

Typically, the values of the binary variable are coded $0 / 1$, the value 1 expressing the occurrence of a particular event, so that the probability of producing that event is estimated based on the values of the independent variables.

The logit model can be written as follows:

$$
\pi(y=1 \mid x)=\frac{e^{\alpha+\beta x}}{1+e^{\alpha+\beta x}} \quad \text { or } \quad \ln \left(\frac{\pi(y=1 \mid x)}{1-\pi(y=1 \mid x)}\right)=\alpha+\beta x
$$

Usually, the $\frac{\pi(y=1 \mid x)}{1-\pi(y=1 \mid x)}$ ratio is noted with $\theta$, and is known in the literature as odds ratio (Freedman, 2009).

For $k$ explanatory variables, the logit model becomes:

$$
\ln \theta=\beta_{0}+\beta_{1} x_{1}+\beta_{2} x_{2}+\cdots+\beta_{k} x_{k}
$$

but most of the times researchers use the multiplicative form of the logit model due to the much easier interpretation of the coefficients:

$$
\theta=\exp \left(\beta_{0}\right) \cdot \exp \left(\beta_{1} x_{1}\right) \cdot \exp \left(\beta_{2} x_{2}\right) \cdot \ldots \cdot \exp \left(\beta_{k} x_{k}\right)
$$

\section{Results and discussions}

The descriptive analysis highlighted interesting aspects of gender stereotypes in the EU member states. The view that women are more likely to decide emotion-based is a common stereotype in the European Union, as can be seen in Figure 1. The highest recorded values are in Hungary, where $86.6 \%$ of women and $89.4 \%$ of men think that women are making decisions based on emotions. At the opposite end we have Spain, where only $47.8 \%$ of men have this opinion, and Sweden, with $54.9 \%$ of women sharing this opinion. In most countries (20 out of 28) we registered a higher proportion of women than men who feel that women are making decisions influenced by emotions. Only in Austria, Romania, Slovenia, Hungary, Slovakia, the Czech Republic, Croatia and Bulgaria were more men who answered yes to this question. In the Netherlands there was the largest gender gap of 14.6 percentage points, with women being more likely to say that women's decisions are based on emotions. 


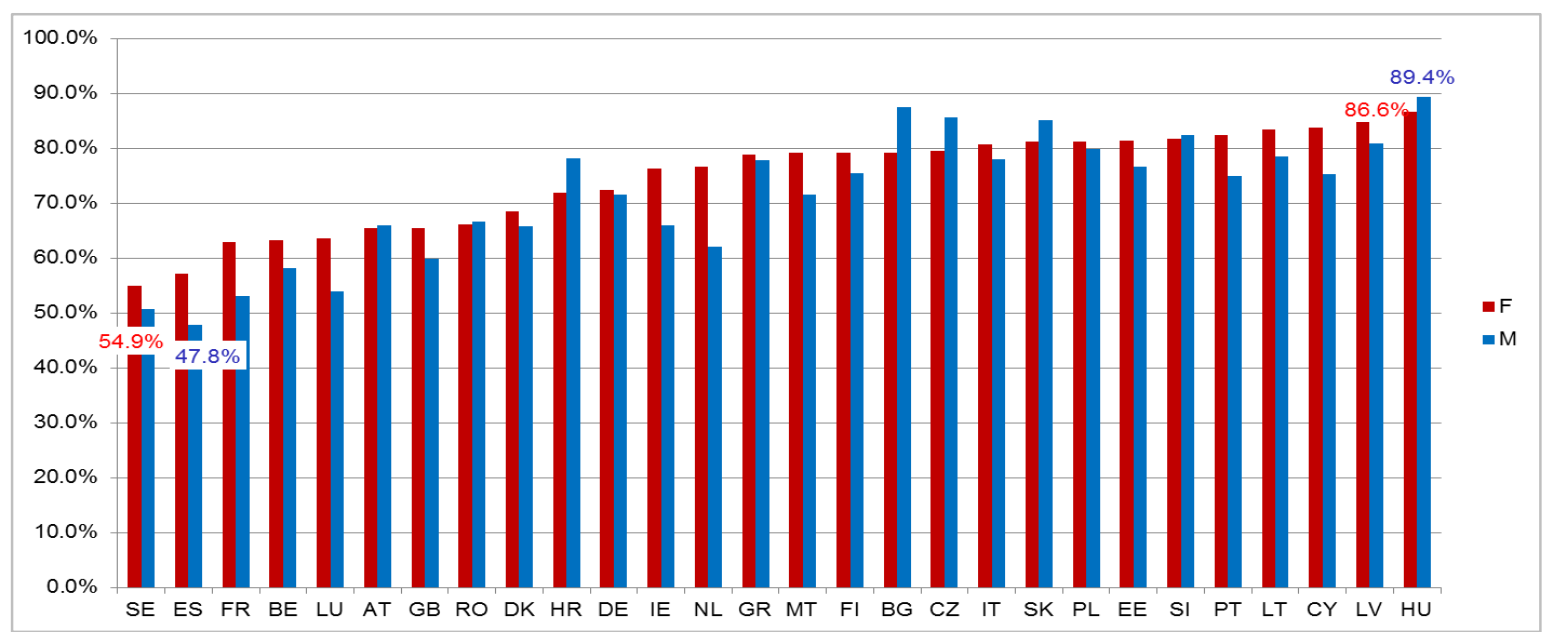

Figure 1. Gender stereotypes - women more likely to decide emotion-based Source: Authors' processing based on Eurobarometer data, $\mathrm{N}=28093$

Regarding the opinion that the main role of men is to earn money, there is a greater variation among EU member states (see Figure 2). In Sweden, there is the lowest share of women who believe that the most important role of men is to earn money (9.3\%), in contrast to Slovakia, where the share of women who had this opinion was the highest $(77.8 \%)$. Sweden also recorded the smallest share of men who consider the most important role of a man is to earn money (17.1\%), while the highest value was recorded in Bulgaria (86.8\%). Generally, the percentage of women who consider that the most important role of men is to earn money was less than the proportion of men who think this, the highest difference being registered in Finland (18.6 percentage points). In Romania, however, the percentage of women who believe that the most important role of the man is to earn money was by 1.9 percentage points higher than that of men with this opinion.

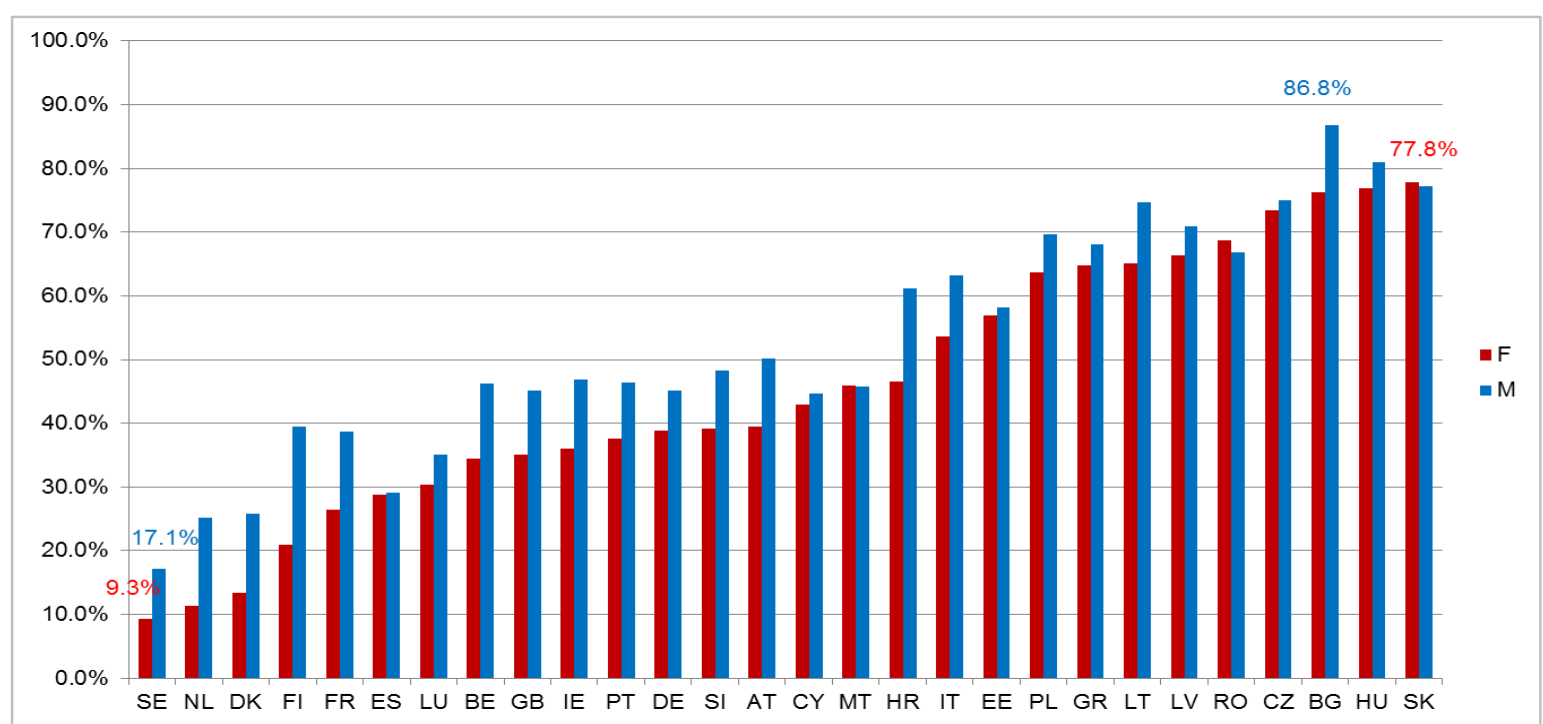

Figure 2. Gender stereotypes - the most important role of a man is to earn money Source: Authors' processing based on Eurobarometer data, $\mathrm{N}=28093$ 
Another relatively common stereotype about gender roles is that the most important role of a woman is to take care of her home and family (see Figure 3). In Sweden there was the lowest percentage of women who believe that the most important role of women is to take care of her home and family (10.3\%) and in Poland the percentage of women who had this opinion was highest (77.7\%). Sweden also recorded the smallest share of men who consider that the most important role of women is to take care of their home and family (14.6\%), while the highest value was registered in Bulgaria (85.9\%). In Romania, the proportions registered are close: $68.4 \%$ for women and $70.4 \%$ for men.

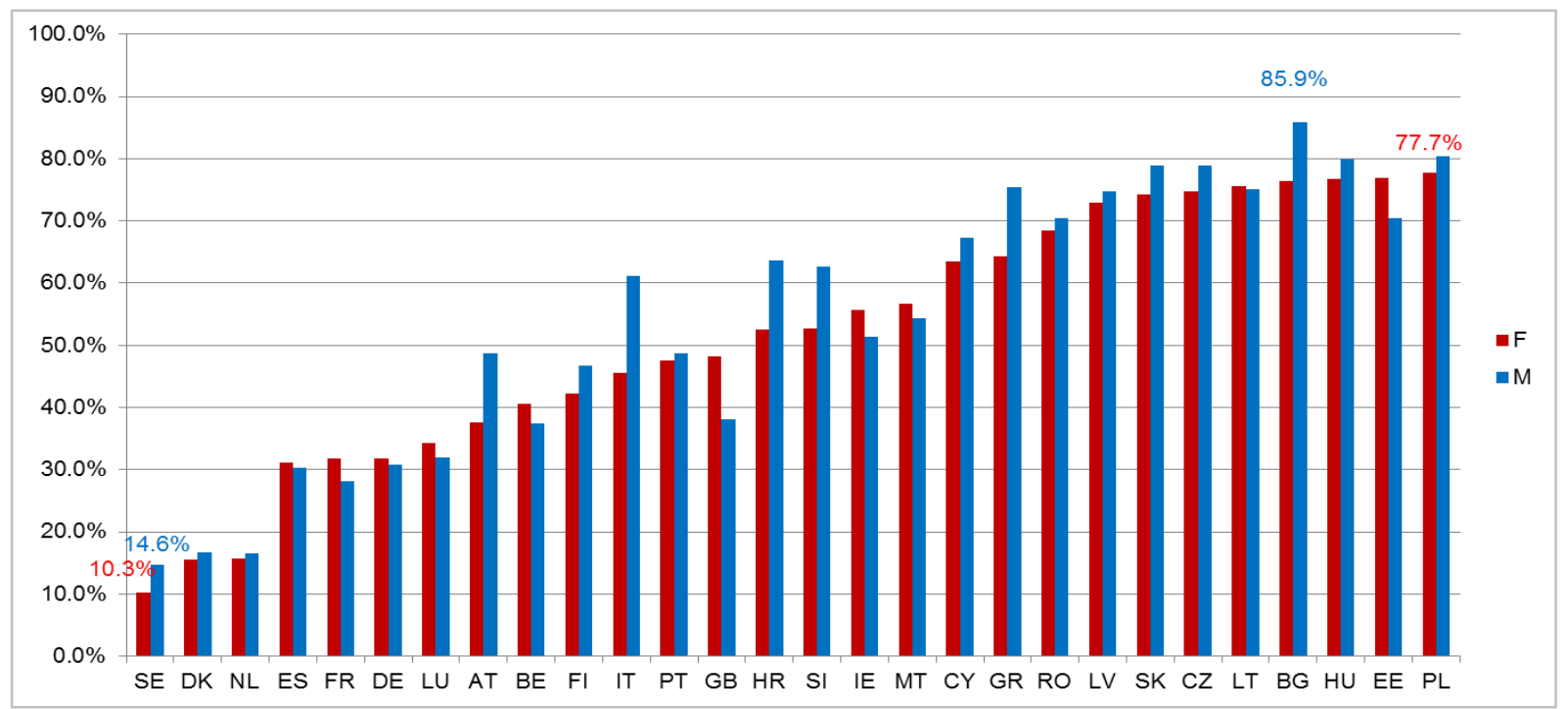

Figure 3. Gender stereotypes - the most important role of a woman is to take care of her home and family

Source: Authors' processing based on Eurobarometer data, N = 28093

Generally, the proportion of women who consider that the most important role of women is to care for her home and family was less than the proportion of men who believe this. The biggest difference was recorded in Italy, with 18.6 percentage points fewer women than men with this opinion. The biggest difference in the opposite direction is observed in the UK, where the share of women who agree with this statement exceeds by 10 percentage points the proportion of men who consider that the most important role of women is to take care of her home and family.

Regarding the perception of gender pay gap, 70.67\% of the respondents think that, taking into account all female and male employees in the economy, women tend to be paid less as men per hour of work, $26.85 \%$ think that women are paid the same as men and only $2.48 \%$ think that women are paid the more than men. The largest share of respondents who consider that women are paid less compared to men per hour of work was registered in Sweden (94.7\%). Also in most developed countries, it seems that people perceive the gender pay gap as a reality of the economy: in Belgium, Spain, Denmark, Finland, France and Netherlands the proportion of the respondents who consider that women are paid less than men exceeds $80 \%$.

We further analysed whether respondents find it acceptable for a woman to earn less than a man. In terms of gender distribution, in Sweden we found the lowest proportion of 
women who consider being acceptable that women are paid less than men (1.19\%), whereas for men the lowest proportion is registered in the Netherlands (2.69\%). The highest values are found in Romania, both for women and men: $21.88 \%$, respectively $30.27 \%$ of Romanian respondents consider it acceptable that women earn less than men for the same job.

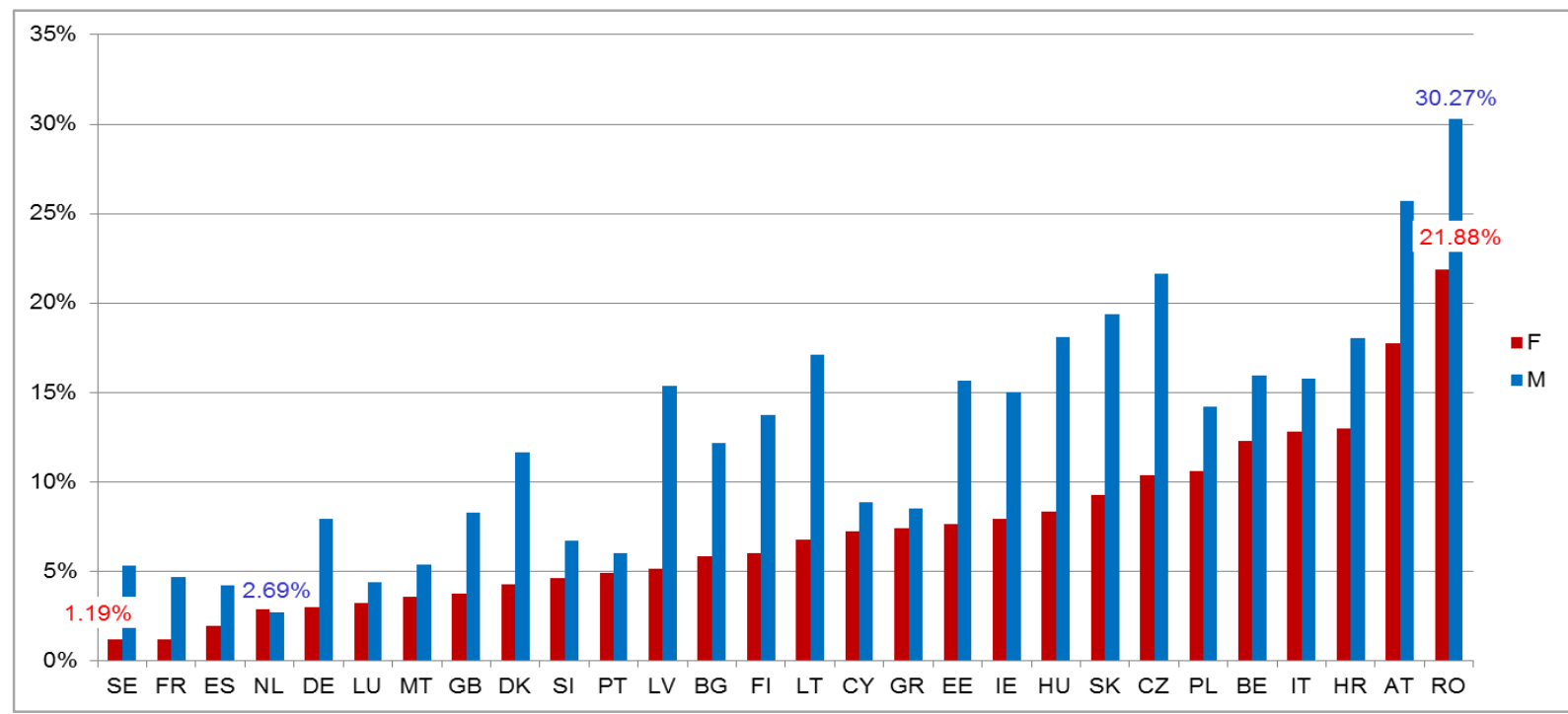

Figure 4. Perception of gender pay gap - the percentage of respondents who consider it is acceptable that a woman is paid less than a male colleague

Source: Authors' processing based on Eurobarometer data

Taking into account the level of education, the hierarchy of EU Member States followed a similar pattern, with the lowest value being registered in Spain (for higher education) and the Netherlands (for those with no tertiary education). For both levels of education in Romania was the highest proportion of respondents who think it is acceptable that a woman is paid less than a male colleague. Although we might expect that higher education graduates to be more egalitarian, it is observed that in 11 Member States the percentage of the respondents who believe that women deserve a lower salary than men for the same job is higher among those with higher education.

\section{Logistic regression analysis of gender pay gap}

Because at EU level the percentage of people who declared that women earn more than men is very low $(2.48 \%)$, we recodified this variable into a binary one considering the answers: men earn more than women (1) respectively between women and men there are no pay differentials (variant coded with 0 ). Using this variable, we continued the analysis focusing on unequal pay to the detriment of women.

As independent variables we used: gender (a binary variable that takes the value 1 for males), age, education (a binary variable that takes the value 1 if the respondent is a higher education graduate), residency (value 1 for urban), marital status (value 1 if the respondent is married, in a consensual union, or lives with the partner), difficulties paying bills (value 1 if the respondent stated that he/she often faces difficulties in paying bills).

The analysis was performed using the SPSS software, the results being presented in Table 1. 
Table 1. Logistic regression model estimation results for EU Member States

\begin{tabular}{|l|c|c|c|c|c|c|}
\hline Variable & B & S.E. & Wald & df & Sig. & Exp(B) \\
\hline Constant & 0.503 & 0.076 & 43.338 & 1 & 0.000 & 1.654 \\
\hline Gender (1=man, 0=woman) & -0.510 & 0.035 & 207.957 & 1 & 0.000 & 0.601 \\
\hline Age & 0.014 & 0.001 & 182.752 & 1 & 0.000 & 1.014 \\
\hline Education (1=tertiary education graduate) & 0.396 & 0.038 & 110.624 & 1 & 0.000 & 1.486 \\
\hline Residency (1=Urban. 0=Rural) & 0.002 & 0.038 & 0.002 & 1 & 0.967 & 1.002 \\
\hline Marital status (1=with partner. 0=single) & -0.023 & 0.038 & 0.361 & 1 & 0.548 & 0.977 \\
\hline $\begin{array}{l}\text { Difficulties paying bills (1=most of the time. } \\
\text { 0=almost never/never) }\end{array}$ & -0.514 & 0.053 & 94.447 & 1 & 0.000 & 0.598 \\
\hline
\end{tabular}

The dependent variable is a binary variable for which: $1=$ women are paid less than men and $0=$ women are paid the same as men

Source: Authors' estimation using IBM SPSS Statistics 21 Note: Number of observations $=17924 ;$ Cox and Snell $R^{2}=0.033$, Nagelkerke $R^{2}=0.049$.

The results indicated that gender is an important factor in explaining the perception of gender pay gap - man are less likely to consider that women tend to be paid less than men per hour of work. Age proved to be statistically significant in our analysis - as they get older, people are more inclined to think that there is a difference in pay in the economy to the detriment of women. Regarding education, higher education graduates have a 1.5 times higher chance of considering that women tend to be paid less than men per hour of work. The persons having difficulties paying bills most of the time proved to be less likely to think that women have lower wages than men for similar jobs. In our analysis, marital status and area of residence were not statistically significant.

\section{Conclusion}

One of the key objectives of human development taken into account by the European Union is the elimination of gender inequalities. This will create conditions for equal access to economic and social resources, will influence the gender balance of the labour force structure and provide equal political representation of women and men. The differences between sexes, whether real or perceived, cause differences in the way people are perceived and appreciated in society, also causing gender inequalities.

The analysis carried out in this study indicated that gender stereotypes are widespread among the citizens of the European Union. Over half of the respondents in all Member States have stated that women are more likely to decide emotion-based, with Hungary accounting for the highest share of those who have this opinion (over 85\%). In terms of gender roles, the most common preconceptions are that the most important role of the man is to earn money and the most important role of the woman is to take care of her home and family. It has been observed that these opinions are more common in the Central and Eastern European countries. On the opposite side, the fewest respondents who agree with these statements are found in Sweden, the Netherlands and Denmark.

We also obtained that nearly three-quarters of respondents think that women are paid less than men per hour worked on the same job. But this vision is a general one; a more in-depth research has shown that there are differences between EU member states. Interestingly, this perception of gender inequality is more pronounced in developed countries, which does not match the official statistical data on gender pay gap. In Luxembourg 
and Belgium, for example, even though statistical data demonstrate that the gender pay gap is between the lowest among European Union countries, the percentage of those who perceive the inequalities is very high, exceeding $70 \%$ in both countries. Also, Sweden is below average in terms of gender pay gap according to the latest report of the European Commission on the subject, but the Swedes perceive otherwise the economic reality: 95\% of them think that women are less paid compared to their male colleagues.

With regard to the socio-demographic profile of people who consider that women are less paid than men for the same type of work, the analysis showed that women are more prone in observing gender inequalities. Also, those with higher education and older people are more likely to think there are wage differences to the detriment of women in the economy.

Gender disparities in terms of pay can generate many negative effects. Lower wages of women can lead to increased economic dependency on the partner, which may increase the risk of domestic violence. Secondly, many women are single mothers and are the sole supporters of the family, so lower wages will increase the likelihood that their families will live in poverty. Also, gender differences in the workplace are transformed into inequality after retirement. As women, on average, live longer than men, they are more likely to live in poverty at old age. Thus, it is particularly important to pay attention to this topic and to design policies aimed at increasing employment among women, reducing discrimination, and providing a balance between work and family life.

\section{Acknowledgements}

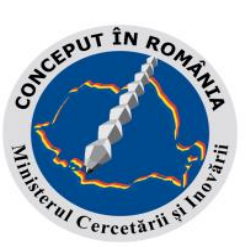

This work was supported by a grant from the Romanian Ministry of Research and Innovation, Program Nucleu PN 19130202, Contract 19N/08.02.2019. "Inegalitatea și instabilitatea veniturilor, discriminare și vulnerabilitate. Implicații asupra bunăstării și rolul politicilor publice", coordinator Eva Militaru.

\section{References}

Beyer, R., Hensersky, T., \& Thomas, A. (2019). The Pay Gap: Pay Inequality but Pay Equity Found in the Construction Industry. Journal of Organizational Psychology, 19(1).

Boll, C., \& Lageman, A. (2018). Gender pay gap in EU countries based on SES (2014). Luxembourg: Publication Office of the European Union.

Costa Dias, M., Joyce, R., \& Parodi, F. (2018). The gender pay gap in the UK: children and experience in work. IFS Working Paper 18/02, 2018.

European Commission, Brussels (2019): Eurobarometer 87.4 (2017). TNS opinion, Brussels [producer]. GESIS Data Archive, Cologne. ZA6924 Data file Version 1.0.0, doi:10.4232/1.13207

EUROSTAT. Gender Pay Gap Statistics. Retrieved from https://ec.europa.eu/eurostat/statisticsexplained/index.php/Gender_pay_gap_statistics

Freedman, D.A., (2009), Statistical Models: Theory and Practice, Cambridge University Press, pp. 128.

GOV.UK. UK Gender Pay Gap. Retrieved from https://www.gov.uk/government/news/ukgender-pay-gap

Ledwith, S., \& Munakamwe, J. (2015). Gender, union leadership and collective bargaining: Brazil and South Africa. The Economic and Labour Relations Review, 26(3), 411-429. 
Leythienne, D., \& Ronkowski, P. (2018). A decomposition of the unadjusted gender pay gap using Structure of Earnings Survey data. Luxembourg: Publications Office of the European Union.

Milner, S., Demilly, H., \& Pochic, S. (2018). Bargained Equality: The Strengths and Weaknesses of Workplace Gender Equality Agreements and Plans in France. British Journal of Industrial Relations, 57(2), 275-301.

Rubery, J. (2015). Intereconomics. Retrieved from https://doi.org/10.1007/s10272-0150527-1.

Trevor, C. O., Teilly, G., \& Gerhart, B. (2012). Reconsidering Pay Dispersion's Effect on the Performance of Interdependent Work: Reconciling Sorting and Pay Inequality. Academy of Management Journal, 55(3), 585-610. 